\title{
Revisiting the effect of statutory pension ages on participation and the average age of retirement in OECD countries
}

\author{
DAVID TURNER, MSc ${ }^{*}$ \\ HERMES MORGAVI, Ph.D.*
}

Article $^{* * *}$

JEL: J26, J21

https://doi.org/10.3326/pse.45.2.4

\footnotetext{
${ }^{*}$ We are grateful for the comments on and discussion of previous empirical work at Working Party No.1 (WP1) of the OECD's Economic Policy Committee, particularly from the Chairman, Arent Skjaeveland, which stimulated the further research summarised here. We are also grateful for comments on an earlier version of the current paper from WP1 delegates, Luiz de Mello, Alain De Serres, Christian Geppert and two anonymous referees as well as Veronica Humi for preparing the document for publication.

${ }^{* *}$ Received: September 29, 2020

Accepted: January 2, 2021
}

\section{David TURNER}

OECD Economics Department, 2 Rue André Pascal, 75016 Paris, France

e-mail: david.turner@oecd.org

ORCiD: 0000-0003-3196-0672

Hermes MORGAVI

OECD Economics Department, 2 Rue Andre Pascal, 75016 Paris, France

e-mail: hermes.morgavi@oecd.org

ORCiD: 0000-0001-8427-3919 


\section{Abstract}

Cross-country estimation work consistently finds that coefficients on statutory pension ages are positive and highly statistically significant in explaining labour force participation at older ages. However, the estimated effects are surprisingly modest when translated into the implied effect on the average effective age of retirement, which typically only increases by about 2 months for every year by which the statutory retirement age increases. This paper shows that grouping countries with similar pension systems, allowing for time heterogeneity and introducing other modelling choices, can improve the estimates of the effect of changes to the pension system. In countries in which there are alternative early retirement pathways or voluntary private pension systems, the effect of changes in statutory retirement ages tends to be dampened. However, for other countries, the effect of changes in statutory pension ages can be around two to three times larger than the typical finding from pooled country estimations.

Keywords: statutory retirement ages, participation, labour supply, older workers

\section{INTRODUCTION}

Many OECD governments have enacted, or are contemplating, future increases in statutory pension ages, in order to contain the rising fiscal costs of ageing, in the context of increasing life expectancy. Empirical cross-country estimation work consistently finds that coefficients on these statutory pension ages are positive and highly statistically significant in explaining labour force participation at older ages. There is also a degree of consistency in the magnitude of the estimated effects across studies although the effect is surprisingly modest when translated into the implied effect on average retirement ages: an increase in statutory pension ages by one year is typically estimated to increase the average effective retirement age by between one and a half and two and a half months. A careful re-appraisal of the magnitude of these effects appears warranted, especially given the vociferous opposition that pension reforms sometimes provoke.

This paper reconsiders the magnitude of these effects by reviewing relevant multicountry studies and by conducting sensitivity analysis around recent empirical work published by the OECD. A broad conclusion is that multi-country studies may seriously underestimate the effect of changes to the pension system, at least for some countries, by not sufficiently allowing for heterogeneity across time and across countries as well as through other modelling choices. For other countries, where the effects of changing legislated ages in the pension system may indeed be modest, this may be indicative of the need to tackle alternative early retirement pathways, or because voluntary private pension systems play an important role in retirement decisions.

The remainder of the paper is organised as follows. The next section briefly reviews a selection of recent multi-country studies that model labour force participation in terms of explanatory variables that include summary parameters of the pension 
system. Section 3 compares the effects of changing statutory pension ages based on these studies with the much larger effects, that can be derived from simple stylised calculations. Section 4 attempts to reconcile these results by conducting sensitivity analysis around recently published OECD econometric estimations. The policy implications of the findings are briefly discussed in section 5 .

\section{A BRIEF REVIEW OF MULTI-COUNTRY STUDIES}

Many cross-country panel studies by OECD and IMF authors have estimated the impact of pension systems, including the role of statutory retirement ages, on labour force participation at older ages. These studies invariably find that coefficients on statutory retirement ages are statistically significant at conventional levels of significance, but it is more difficult to assess how important the magnitude of these coefficients is from a policy perspective or to compare the coefficients across studies. This is partly because the dependent variable often differs across studies (for example different age groupings are considered or the functional form of the dependent variable differs), but more fundamentally it is difficult to assess whether the size of these coefficients are "small" or "large" from a policy perspective because no obvious benchmark is provided. To overcome these problems the current paper evaluates these effects using a common metric (as described in detail in appendix A), namely the effect on the average effective age of retirement, measured in months, of raising statutory pension ages by a single year.

Earlier studies, with sample periods mainly covering the 1970 s to 1990 s, emphasised the importance of modelling the interaction between the old-age pension system and other social protection and labour policies. Blöndal and Scarpetta (1999) demonstrate the importance of unemployment-related and disability schemes in explaining the participation rate of males aged 55-64 in OECD countries over the period 1971-95. The importance of these de facto early retirement schemes, helps to explain why the effect of statutory retirement ages in their pooled regressions, although statistically significant, are calculated (by the present authors, see appendix A) to be small: an increase in statutory pension ages by 1 year implies an increase in the average effective retirement age by only 1.1 to 1.4 months. Duval (2004) also found that social transfer programmes outside the old-age pension system, which were particularly prevalent in most continental European countries, acted as de facto early retirement schemes with a marked impact on the participation rate of men aged $55-59$, but also with effects on the participation rate of men of older ages. In addition, statutory pension ages are found to have a statistically significant impact on the participation of men in the age groups 60-64 and 65-69, but the size of the implied effect on the average effective age of retirement is again modest (according to calculations by the current authors, see appendix A): an increase in the statutory retirement age by 1 year only raises the effective age of retirement by 1.4 months.

The effect of increases in statutory pension ages has also been evaluated as part of a much broader exercise to assess the impact of a range of structural labour market policies and institutions on participation or employment, over sample periods which typically begin in the 1980s. A recent OECD study, Gal and Theising (2015), used 
cross-country panel regressions to assess the effectiveness of a range of structural labour market policies in promoting employment in OECD countries. As part of this study, separate cross-country panel regressions are estimated to explain the employment rate of the group aged 55-64 and it is reported that the statutory retirement age lifts the employment rate of the elderly "by a statistically and economically significant margin". However, in comparison with the effectiveness of all other structural labour market policies using these same results, carried out by comparing the effect of a "typical" change in each policy instrument, the statutory pension age is found to have the smallest effect on the aggregate employment rate of any structural policy considered (Egert and Gal, 2017). Such a modest effect is confirmed by calculations in this paper, which suggest the estimated coefficient implies that an increase in the statutory pension age by one year would result in an increase in the average effective retirement age of only 1.4 months (see appendix A). A similar wide-ranging IMF study, Grigoli, Koczan and Tapalova (2018), considers the effect of a broad range of policies, institutions and secular trends on aggregate labour force participation. As part of this study, a panel regression to explain labour force participation of those aged over 55 in 23 advanced economies finds a statistically significant effect from the statutory pension age, which prompts a comment from the authors that "incentives for retirement have a powerful effect on labour force attachment". However, following a hypothetical one-year increase in the statutory retirement age, this coefficient implies an increase in the average effective age of retirement of only 2.2 months (see appendix A).

A recent OECD study, Geppert et al. (2019), considers the determinants of labour force participation, distinguishing participation effects by both sex, education and single year of age. This study is of particular interest here because it provides the baseline for the analysis in the remainder of this paper (and so is described in further detail below). Nevertheless, a key finding for present purposes is that, despite the more detailed modelling of participation, an increase in the statutory pension age by one year only raises the average effective age of retirement by 2.4 months.

In summary, the results from cross-country panel regressions consistently imply that the statutory retirement age has only a rather modest effect on the average effective retirement age, which would seem to be at odds with the importance usually given to pension reforms. These findings of modest effects also seems to be contradicted by quantifications based on pension reforms in individual countries. Siebold (2019) analyses the concentration of retirements around statutory ages in Germany and concludes that "an increase in the normal retirement age from 65 to 66 is predicted to lead to an increase in average actual retirement ages by 4 months". Mastrobuoni (2009) discusses a policy change in the United States that increased the normal age of retirement from 65 to 67 and raised the penalty for claiming retirement benefits before then, concluding that an increase in the normal retirement age by 2 months delays effective retirement by around 1 month. Staubli and Zweimüller (2013) analyse pension reforms in Austria that increased the early retirement age from 60 to 62 for men and from 55 to 58 for women, concluding that this increased employment by 10 percentage points among affected men and by 11 percentage points among affected women. 


\section{Figure 1}

Comparing policy effects of a stylised shift in participation and econometric predictions - Effect of a one-year increase in statutory retirement ages on participation rates, German males, 2015 (\%)

(a) With stylised shift

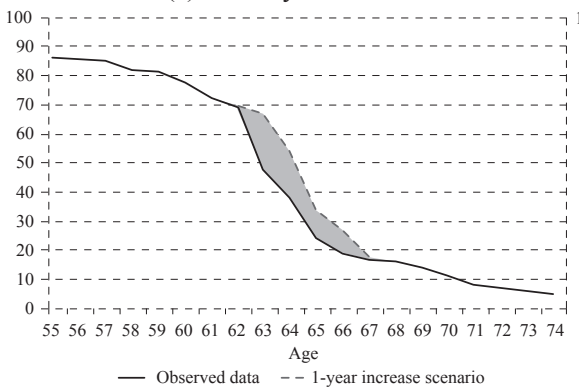

(b) Using panel estimation

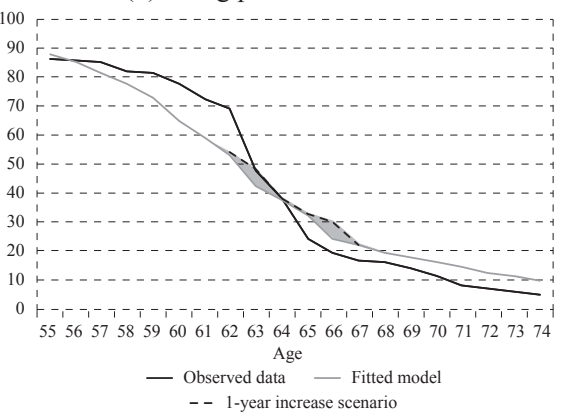

Note: Both panels illustrate the estimated effect of a one-year increase in both the statutory minimum and normal retirement ages. Panel A uses a stylised shift in the actual age-participation profile, whereas panel $B$ uses the baseline pooled-country estimated equation reported in Geppert et al. (2019). The size of the effect on labour force participation and the average retirement ages is proportional to the shaded area.

Source: Authors'calculations.

Before a further estimation to try to resolve these apparent contradictions, it is helpful to visualise the problem with a concrete example. A rough estimate of the effect of a change in statutory pension ages can be gauged by considering a stylised shift in the age-participation profile. For some countries, there is a pronounced drop in labour force participation between the minimum age of retirement ${ }^{1}$ and the normal age of retirement, ${ }^{2}$ as illustrated for the case of German men in figure 1, panel A. For the purposes of a stylised calculation, it is assumed that an increase in statutory pension ages by one year simply shifts the age-participation profile between these two ages by one year (as illustrated by the dashed line in figure 1, panel A). This is achieved by assuming that: participation rates at each age before the original minimum retirement age remain unchanged; for subsequent ages, the percentage change in the participation rate between each age and the following one is shifted up one year; and participation rates after the new normal retirement age remain unchanged. The total increase in the participation rate from such a stylised calculation, represented by the shaded area in panel A, is equivalent to an increase in the participation rate of the group aged 55-74 of 2.1 percentage points, and translates into an increase in the average retirement age of 5.1 months. This stylised calculation can be compared with the effect of an alternative computation using the baseline model fitted by pooled economic estimation in Geppert et al. (2019), (figure 1, panel B). Firstly, it should be noted that the fitted model from the pooled estimation implies a more gradual fall in participation than the more

\footnotetext{
${ }^{1}$ The minimum retirement age is defined as the age at which an individual who entered the labour market at age 25 and had a full career becomes eligible for a (reduced) pension from a mandatory pension scheme.

${ }^{2}$ The normal retirement age is defined as the age at which an individual who entered the labour market at age 25 and had a full career becomes eligible for a full pension from all mandatory pension schemes.
} 
sudden drop from the minimum retirement age in the actual data. Then, applying the policy shock of increasing statutory pension ages results in a more modest shift in participation, equivalent to an increase in the participation rate of the age group 55-74 of 0.7 percentage points, equivalent to an increase in the average retirement age of only 1.5 months. The much larger (more than three-fold) increase from the stylised calculation compared to using the pooled econometric estimate is illustrated by the shaded area being much larger in panel A than panel B.

\section{REASONS WHY PENSION EFFECTS MAY BE UNDER-ESTIMATED IN MULTI-COUNTRY STUDIES}

\subsection{THE BASELINE MODEL}

In order to try to reconcile the stylised calculations of the effect of an increase in statutory retirement ages with the results from pooled estimations, this section reports a series of variant pooled estimations. The starting point is the baseline equation reported in Geppert et al. (2019), which is reproduced here as equation [1] in table $1 .^{3}$ An important distinguishing feature of this recent study is that the dependent variable is the participation rate by single year of age (rather than by five-year, or larger, age grouping), for each age between 55 and 74, distinguishing also by the level of education (low, medium and high) as well as by gender. The data cover 26 countries, mostly in the European Union, but also Switzerland, Canada and the United States. The participation rate $\left(P R_{i, s, a, e, t}\right)$ is modelled by country $i$, sex $s$, age $a$, education level $e$ and year $t$ using the following equation:

$$
P R_{i, s, a, e, t}=\alpha_{i}+\gamma_{s}+\theta_{a}+\rho_{e}+\gamma_{s} \rho_{e}+\gamma_{s} \theta_{a}+\rho_{e} \theta_{a}+\sum_{j} \beta_{j} X_{i, s, a, e, t, j}
$$

where $a_{i}$ is a country fixed effect, $y_{s}$ a gender fixed effect, $\theta_{a}$ an age fixed effect, $\rho_{e}$ an education fixed effect, $y_{s} \rho_{e}$ a sex-education interaction effect, $y_{s} \theta_{a}$ a sex-age interaction effect, $\rho_{e} \theta_{a}$ an education-age interaction effect, the $X_{j}$ are explanatory variables of interest and $\beta_{j}$ their associated coefficients. The sample period spans 1990 to 2017, but the panel is unbalanced.

Explanatory variables include direct policy drivers, secular trends and control variables:

- The direct policy drivers are statutory retirement ages (minimum and normal) and pension wealth. The latter captures policy-driven financial retirement incentives, but is not fully comprehensive. Both indicators consider only mandatory retirement pension systems and not the full array of social security programmes that may affect the retirement decision, notably unemployment insurance and disability schemes, nor the effect of voluntary private pension schemes.

- Secular trends include life expectancy as well as the percentage of a population group with tertiary education.

\footnotetext{
${ }^{3}$ This is also equation [1] of table 2 in Geppert et al. (2019), which is the equation they chose for a subsequent historical decomposition analysis.
} 
- The unemployment gap is included as a control variable, but as a five-year moving average to account for the sluggish response of participation to cyclical developments.

In subsequent sections of this paper, variant estimations are undertaken around the baseline equation with a focus on the sensitivity of the estimated coefficients on statutory retirement ages and their implications for average effective retirement ages and labour force participation following a reform in statutory pension ages.

\subsection{MODELLING ISSUES}

Age fixed effects are included in the baseline model (as they often are in pooled regressions modelling participation) in order to capture social-cultural influences that may be similar across countries, but are difficult to capture with more specific quantitative explanatory variables. These age fixed effects show a steeper drop between the ages of 60 and 65 , when most old age pensions are first claimed, than either before 60 or after 65 (figure 2); for men, the rate of decline in the age fixed effects over the ages 60 to 65 is more than three times the rate of decline after 65 . While these fixed effects are intended to capture influences that are entirely separate from the pension system, it is also arguable that such social-cultural norms are conditioned by the ages at which old-age pension systems typically operate. Replacing these fixed effects with either a linear or a quadratic age variable - which might seem a more natural choice for modelling other gradually evolving social-cultural considerations exogenous to the pension system - increases the explanatory power and coefficients on estimated statutory pension ages. It consequently increases the estimated average retirement effect by about one-third (figure 3, panel A; and from a comparison of equations (2) and (3) with the baseline equation (1) in table 1).

\section{Figure 2}

Age fixed effects in the baseline model - Effect on labour force participation at different ages (percentage points)

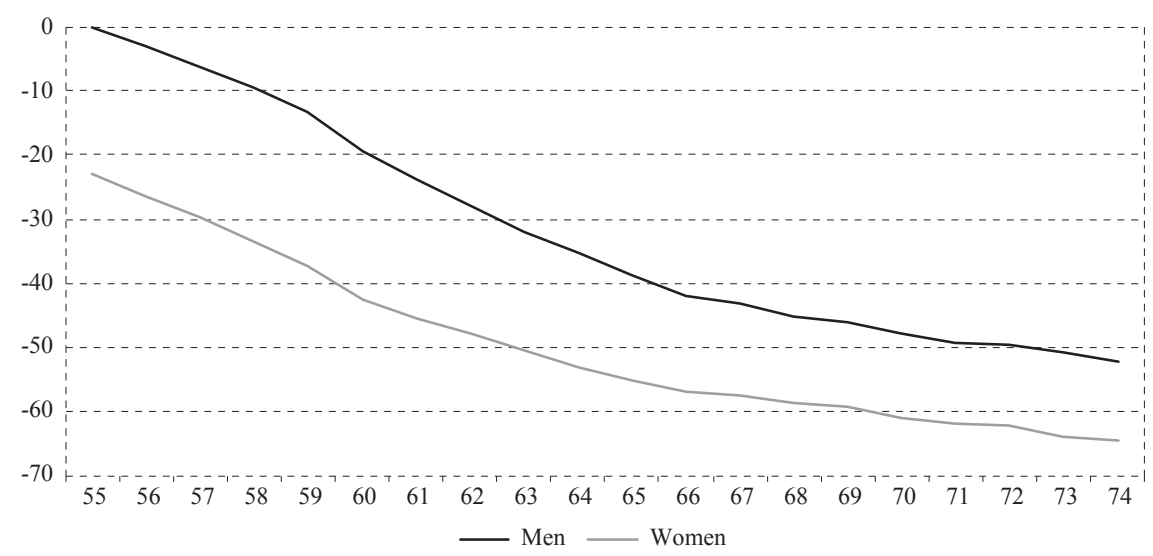

Note: Age fixed effects from the baseline model, taken as equation [1] in table 1 of Geppert et al. (2019).

Source: Authors' calculations. 
In the baseline model, the influence of statutory retirement ages is modelled with two sets of dummy variables (figure 4, panel A): the first takes the value of unity at ages equal to and above the minimum retirement age; the second takes the value of unity at ages equal to and above the normal retirement age. This implies an abrupt effect on participation at the minimum and normal retirement ages (figure 4, panel B). An alternative way of modelling the effect of statutory retirement ages is to include a "transition to retirement" variable, which implies a more gradual effect on participation between the minimum and normal retirement ages (figure 4, panels $\mathrm{C}$ and $\mathrm{D}$ ). The replacement of the dummy variables by the transition variable generates a similar goodness-of-fit, but a slightly larger effect of the statutory retirement ages on participation (figure 3, panel A; and a comparison of equations (2) and (4) in table 1).

\section{Figure 3}

Estimated effect on the average effective retirement age of an increase in the statutory retirement age of one year

(a) Sensitivity to modelling choices

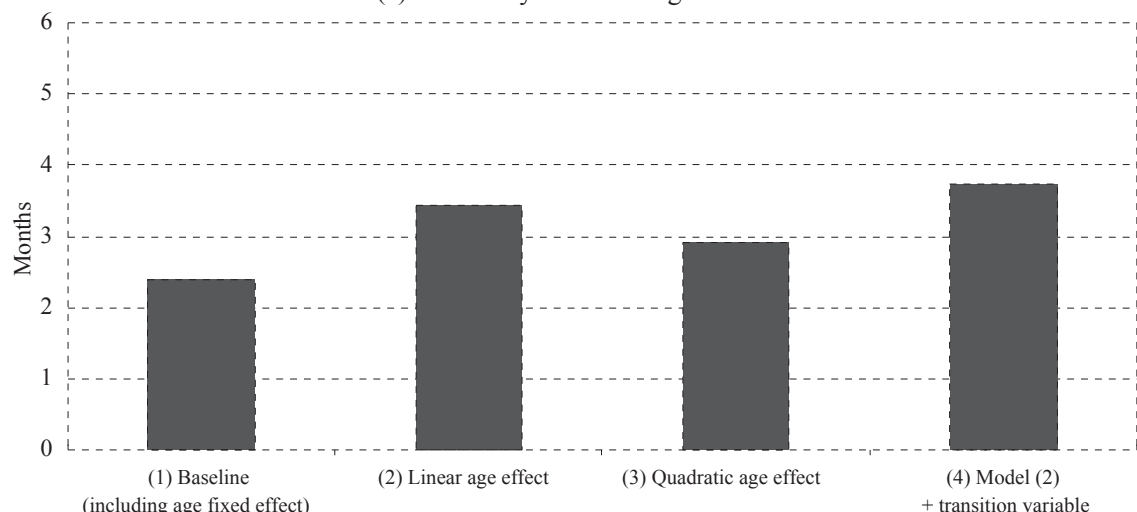

(b) Sensitivity to country heterogeneity

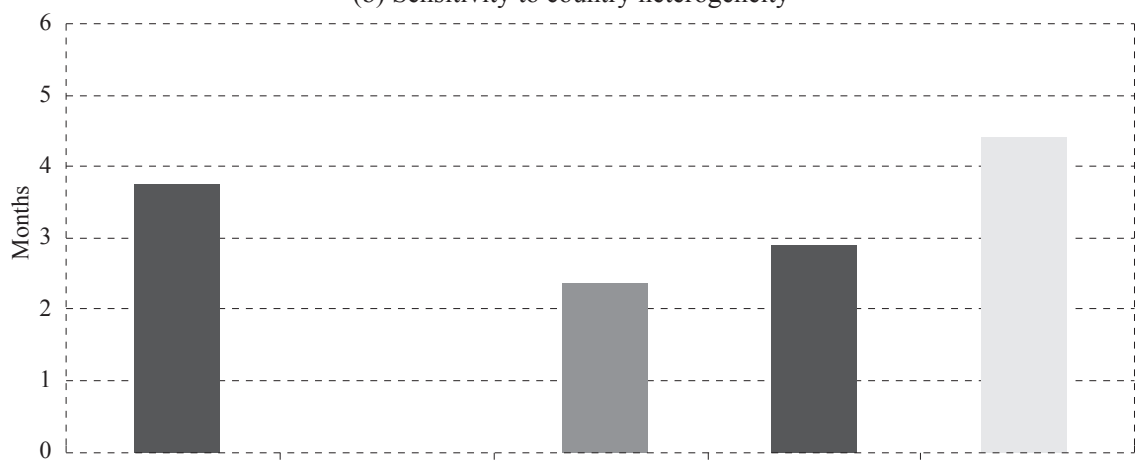

$\begin{array}{llll}\text { (4) All countries } & \text { (5) Private pensions } & \text { (5) Early retirement } & \text { (5) Majority }\end{array}$ 
(c) Sensitivity to sample period

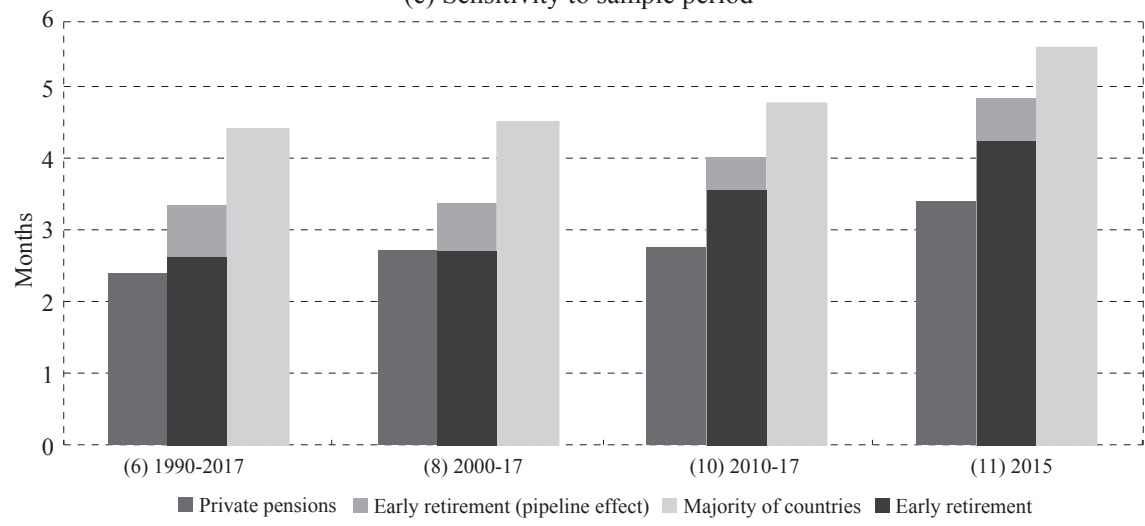

Note: The number in brackets at the start of each label on the x-axis refers to the equation number in table 1. Successive bars in each panel show the effect of changing one characteristic relative to previous bars.

\section{Figure 4}

\section{Modelling of statutory retirement ages}

(a) Dummy variables

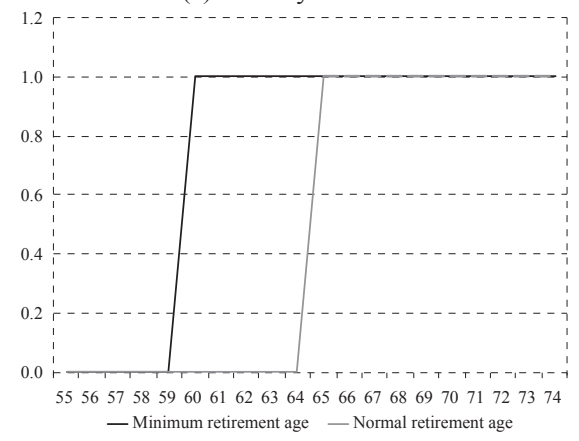

(c) Effect of dummies on participation rate

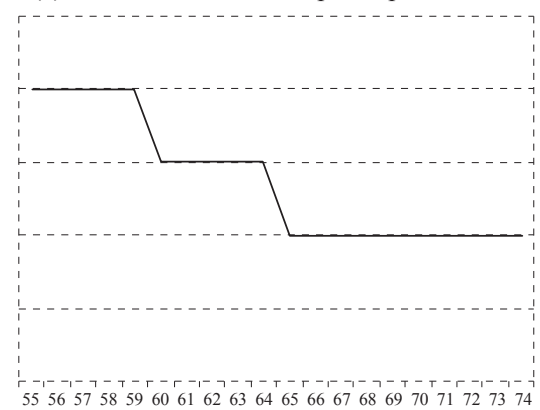

(b) Transition to retirement variable

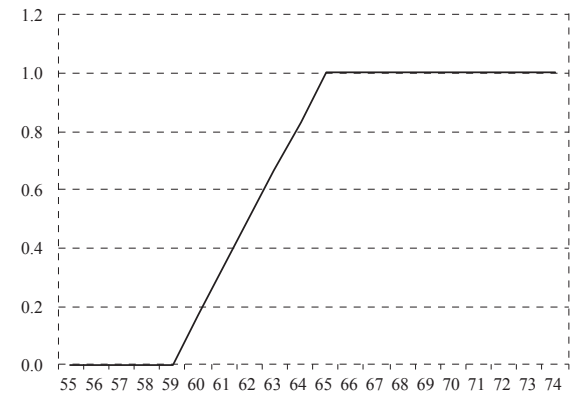

(d) Effect of transition to retirement variable on participation rate

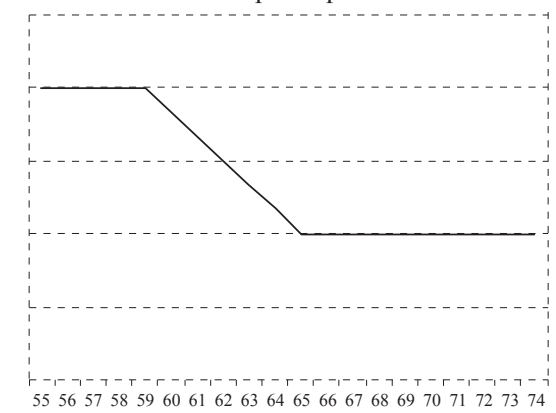

Note: The figures illustrate alternative ways of modelling statutory retirement ages when the minimum retirement age is 60 and the normal retirement age is 65 .

Source: Authors' calculation. 
A final modelling issue relates to possible multicollinearity: if statutory pension ages have broadly increased with life expectancy (indeed in some cases, reforms have explicitly linked the two), then including both variables in any regression may result in an identification problem, which may contribute to a lower coefficient on statutory retirement ages. While this sounds reasonable, on the current dataset, statutory retirement ages have not kept up with life expectancy in most countries. Moreover, there is large variation in this difference across countries, which would suggest that multicollinearity ought not to be a problem (see figure 6 in Geppert et al., 2019). Moreover, variant equations in which the life expectancy variable was either dropped or replaced with a time trend did not result in a higher coefficient on the statutory pension age variables. Nevertheless, the possible link between these variables should not be ignored in interpreting the results: for example, it seems quite likely that if life expectancy were to stop increasing, then changing the statutory retirement age might be less effective. 


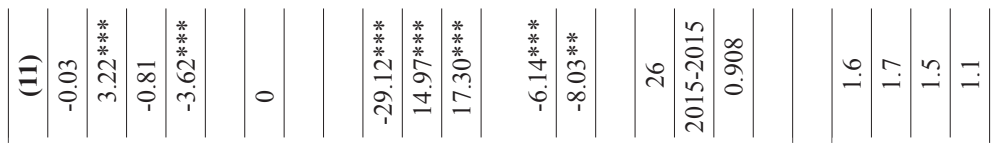

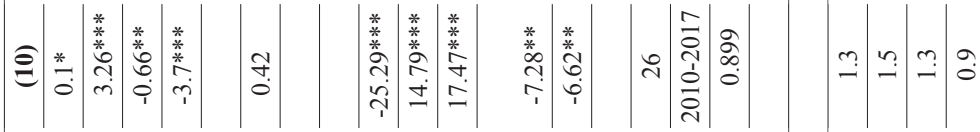

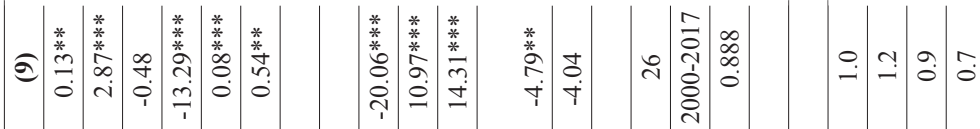

כ

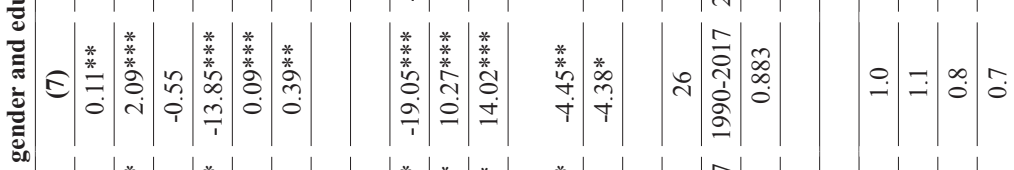

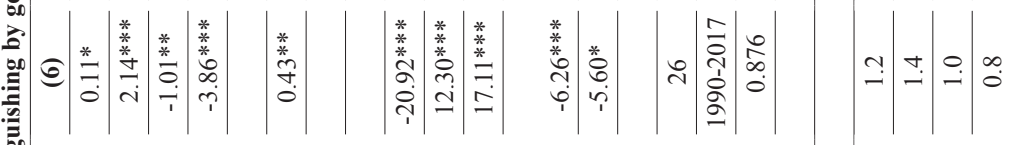

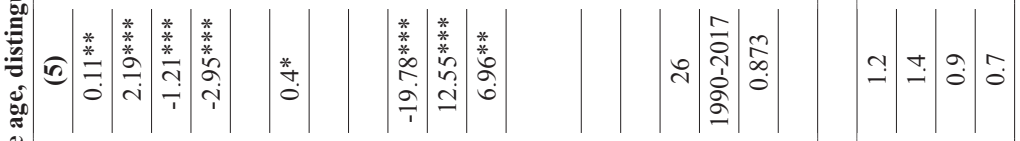

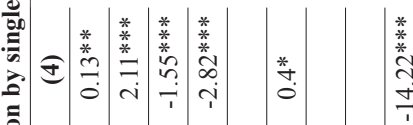

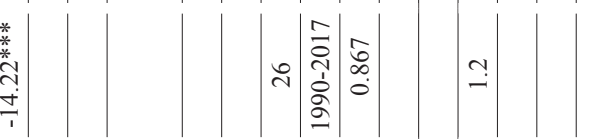<smiles>C#CC#N</smiles> 


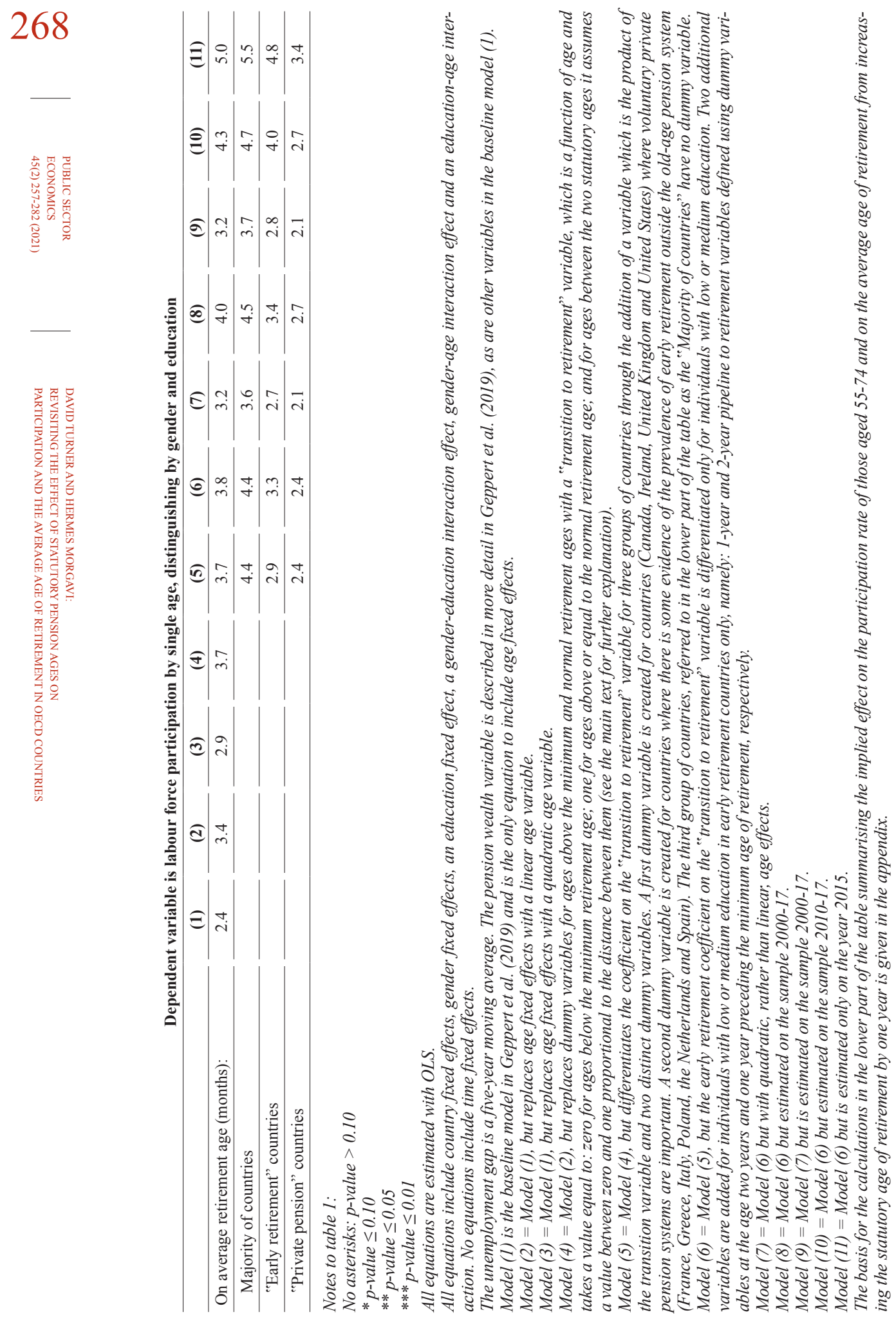


The estimates from pooled regression represent average responses across countries, but, if there is great heterogeneity in pension systems across countries, this might be unrepresentative of any particular country. This section explores the sensitivity of the coefficients on statutory retirement ages to changes in the composition of the country sample by grouping countries based on the particular characteristics of their pension systems.

As noted above, a focus of earlier studies of older age participation was the influence of other social transfer systems, outside the old-age pension system, in providing de facto early retirement pathways. Around the mid-1990s, there was a shift of emphasis from compensation to integration in sickness and disability policies across many OECD countries (OECD, 2010). While this has undoubtedly resulted in the tightening of early retirement pathways, it is likely that they still play a role in some countries.

For some countries, the average "effective" retirement age is less than the "minimum" retirement age (the age at which a worker is first entitled to a pension), suggesting that the use of alternative early retirement pathways is widespread and likely to dampen the effect of any changes to the old age pension system. For the purposes of the current estimation, countries are characterised as having a prevalence of early retirement opportunities if the average effective retirement age is below the minimum retirement age for both men and women over the period 2012-17. Among the countries in the baseline sample, this includes Greece, Spain, France, Italy, Poland and the Netherlands. ${ }^{4}$

In those countries where voluntary private pensions are important - here taken to include Canada, Ireland, the United Kingdom and the United States - changes to the statutory ages of the mandatory system are likely to have smaller effects on labour force participation. ${ }^{5}$

In order to allow for differential effects from changes in statutory ages for these different groups of countries, two distinct dummy variables are created (one for

\footnotetext{
${ }^{4}$ This classification of countries for which early retirement pathways are considered important is not clear-cut. For example, if the criteria is extended to be that the average retirement age is below the minimum retirement age for either men or women (rather than both), then Belgium, Luxembourg and the Slovak Republic would also be included. Ebbinghaus (2006) finds evidence confirming marked early retirement patterns for Italy, France and the Netherlands, with respect to Nordic and Anglophone countries over the period 1970-2005, but additionally finds such evidence for Germany. Duval (2004) additionally identifies Austria, Germany, Luxembourg and Portugal as having important alternative early retirement pathways. However, as discussed in section 4.4, it is possible that early retirement pathways have been tightened in some of these countries since the studies were published. For example, as documented in Börsch-Supan and Jurges (2012), policy changes in the 2000s substantially tightened access to early retirement pathways in Germany. In any case, sensitivity analysis varying the criteria for selecting this group of countries does not much affect the overall estimation results, although clearly it does have important policy implications for the countries concerned.

${ }^{5}$ For the purposes of the current estimation, countries are characterised as having an important voluntary private pension system if voluntary private pensions cover a large share of the working population and the replacement rate from such schemes is at least $60 \%$ of that in the public mandatory pension scheme. Using data from tables 5.3 and 9.1 in OECD (2019), this group includes Canada, Ireland, the United Kingdom and the United States.
} 
countries where private pensions are important and one where there is evidence that alternative early retirement pathways are important) and interacted with the transition-to-retirement variable previously described. Allowing for this differential effect leads to a marked dispersion in the effect of changes in statutory retirement age on average effective retirement (figure 3, panel B; and comparing equations (4) and (5) in table 1). Countries that are not classified as having important private pension systems or alternative early retirement pathways - hereafter referred to as the "majority of countries" - show an effect on the average effective retirement age; this is two-and-a-half-times that of countries where private pensions are important and nearly half as much again as early retirement countries.

Some alternative early retirement pathways may work by providing a "pipeline" to retirement under the regular old age pension system. That is, other social security programmes may provide a strong incentive to retire a year or more in advance of the statutory retirement age and then when the statutory retirement age is reached retirement is possible under the old age pension system. Some evidence for such a pipeline effect is found in the previously classified "early retirement" countries because two pipeline variables - defined as dummy variables in the year immediately preceding the minimum retirement age and two years preceding the minimum retirement age - are highly statistically significant for these countries. Further estimation suggest that individuals with low and medium education are more prone to early retirement than those who are highly educated, confirming the findings of Siegrist et al. (2006) and Fischer and Sousa-Poza (2011). Thus, including the early retirement dummies and pipeline variables only for individuals with low or medium, rather than high, education further improves the fit of the estimated model (equation (6) in table 1). Similar pipeline variables when included for either "private pension" countries or the majority of other countries are smaller and statistically insignificant (and so are not included). The pipeline variables for the early retirement countries boost the effect of an increase in the statutory retirement age if the pipeline variables shift with the change in the statutory retirement ages (compare equations (5) and (6) in table 1), as assumed in the lower part of table 1.

While not the focus of the current paper, the variant equations can also be used to provide a crude estimate of the effect on participation and the effective age of retirement from the elimination of alternative early retirement possibilities for a typical country, although better country-specific estimates are likely to be obtained by considering the detail of individual schemes on a country-by-country basis. To generate such an estimate it is assumed that: the pipeline variables are eliminated; the coefficient on the transition-to-retirement variable becomes the same in the "early retirement" countries as the majority of countries; and the average country fixed effects in the "early retirement" countries becomes the same as in the majority of countries. On this basis, elimination of alternative early retirement possibilities might be expected to increase the average effective age of retirement by up to 20 months for workers with low and medium education (figure 5), which is equivalent to an overall aggregate increase of 18 months. 


\section{Figure 5}

The simulated effect of eliminating early retirement pathways - Stylised ageparticipation profile of low-and medium-educated workers

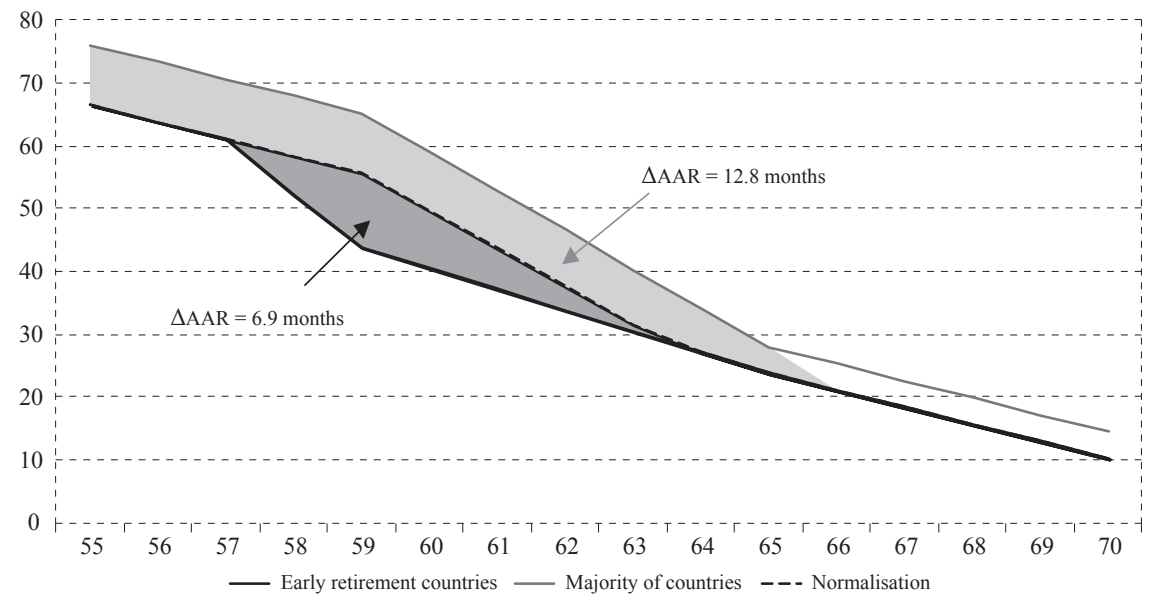

Note: The chart compares a stylised age-participation profile of low and medium-educated workers in countries classified as "early retirement" countries with those in the majority of countries. The profiles are generated using equation (6) in table 1, using: differential responses to the minimum and normal statutory ages of retirement, which for the purposes of this example are assumed to be 60 and 65: the pipeline effects (for early retirement countries only); common linear age effects; a constant difference between the two groups of countries equal to the difference in the average country fixed effects for each group. The black dashed line (and black shaded area) simulates the effect of eliminating early retirement pathways on the assumption that the response of early retirement countries to statutory ages becomes the same as the majority of countries and the pipeline effects are eliminated. A shift to the gray line (and gray shaded area) further assumes that eliminating early retirement pathways would also imply the average country fixed effect for early retirement countries becomes the same as for the majority of countries. These two effects combined would imply an increase in the average participation rate for the age group 55-74 of 6 percentage points and an increase in the average age of retirement ( $\triangle A A R)$ by 20 months.

\subsection{SAMPLE ISSUES: TIME PERIOD COVERAGE}

The sensitivity of results to the sample estimation period is investigated, not least because there has been, since the mid-1990s, a tendency towards the tightening of early retirement pathways in many OECD countries. Börsch-Supan and Coile (2018) documenting pension reforms in 12 major OECD countries, report that public programs that offer a pathway to retirement outside the old age pension system have been tightened in nine of the 12 major OECD countries they consider, usually with a series of reforms.

The example of Germany is illustrative of the effect that tightening early retirement pathways can have on the age profile of the participation rate and hence the sensitivity of estimation results to the sample period. Over the period 1990-2012, the minimum and normal retirement ages were unchanged, after which the normal retirement age increased modestly. Over the same period, the effective retirement age fell over the first half of the 1990s and then steadily rose in the following years (figure 6, panel B). This can be partially explained by several reforms carried out in the 1990s and in 
the 2000 s, which reduced the incentive to early retirement, as discussed in more detail in Börsch-Supan and Jurges (2012). Between 2003 and 2005, the Hartz reforms "dramatically shortened the duration of unemployment benefits, especially for older individuals and made unemployment benefits insurance much less attractive as a substitute for early retirement". This was accompanied by shifting the age limit for old-age pensions due to unemployment to age 63 (from 60). In 2007, the limit for old-age pensions for the disabled was shifted to 65 years. The cumulative effects of the implementation of these reforms are evident in the evolution of the age profile of the participation rate. In the year 2000, the steepest fall in participation rate for men was between the ages of 59 and 60, well before the minimum age of 63 (figure 6, panel A). However, by 2015 the steepest fall is at the minimum retirement age of 63, with further steep falls until the normal age of retirement at $65 .^{6}$ Thus, the tightening of early retirement pathways means that the influence of the old age pension system is much more apparent in the age-profile of participation.

Shortening the sample estimation period - from 1990-2017 to 2000-17 to 2010-17 and to a single year 2015 - further increases the estimated coefficients on statutory pension ages (figure 3, panel C; and a comparison of equations (6) to (11) in table 1). The implied effect on the average age of retirement from a one-year increase in statutory pension ages rises for all country groups identified in the estimation as the sample period is shortened, but by most for the early retirement countries.? Thus shortening the sample estimation period from 1990-2017 to 2010-17, raises the average age of retirement effect from 4.4 to 4.7 months for the majority of countries, but from 3.3 months to 4.0 months for early retirement countries, and only from 2.4 to 2.7 months for private pension countries.

\section{Figure 6}

\section{The evolution of labour force participation and retirement ages in Germany}

(a) Male labour force participation rate by age

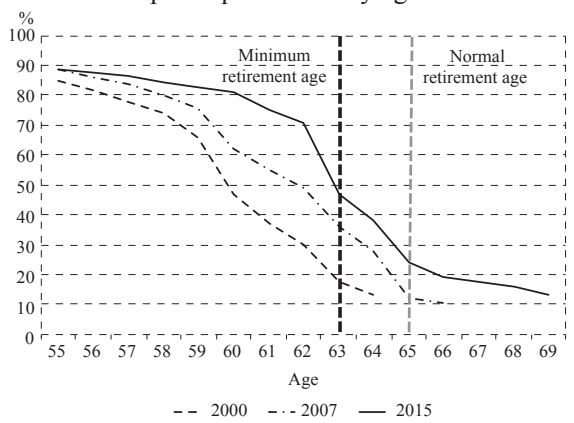

(b) Statutory and average effectiveretirement age

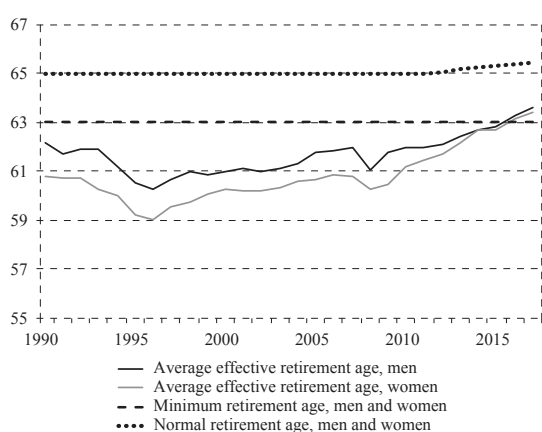

Source: OECD (2019), Eurostat and authors' calculations.

\footnotetext{
${ }^{6}$ This also helps to explain why Germany had a large positive residual in the historical decomposition analysis to explain the change in participation rates between 2002-2017 in Geppert et al. (2019), since their model did not factor in the effect of tightening early retirement pathways on boosting participation.

${ }^{7}$ The United States and Canada, here classified as countries where private pensions are important, are also two (of the three) major OECD countries considered by Börsch-Supan and Coile (2018) that have not tightened early retirement pathways since the 1980 s.
} 
With many OECD countries already facing the prospect of rising debt burdens in the wake of the current corona-crisis, increasing statutory retirement ages would seem an obvious policy response to cope with the rising fiscal costs associated with ageing populations, particularly if life expectancy continues to increase. At the same time, such policy changes have often faced vociferous opposition, perhaps because they are easily understood and impact so widely, suggesting that weighing the benefits and costs will be important for any policy-maker considering action.

The current paper suggest that the results from multi-country panel regressions are likely to seriously understate the benefits of changes in the statutory retirement age in terms of the positive effects on labour force participation and the average age of retirement, perhaps by a factor of two to three, unless they carefully take into account heterogeneity across countries and through time. A sensitivity analysis of previous cross-countries empirical estimates shows that some modelling choices can be the cause of such under-estimation:

- Estimated age fixed effects show a marked drop between the ages of 60 and 65 , when most old age pensions are first claimed. Replacing these fixed effects with either a linear or a quadratic age variable increases the coefficients on estimated statutory pension ages.

- Grouping countries according to the characteristics of their pension systems, rather than pooling all countries together, improves the goodness of fit of the estimates and returns coefficients that better reflect the impact of changes in statutory pension ages. In those countries where voluntary private pensions are particularly important, changes to the statutory ages in any mandatory system are likely to have smaller effects on labour force participation. For some other countries the average effective retirement age is much less than the "minimum" retirement age (the age at which a worker is first entitled to a, usually reduced, pension), suggesting that the use of alternative early retirement pathways is prevalent and likely to dampen the effect of any changes to the old age pension system. If the estimation allows for heterogeneous coefficients, the estimated effect of changing the statutory retirement age is substantially reduced for both groups of countries, whereas the effect for the majority of other countries significantly increases.

- Many countries have tightened access to alternative early retirement pathways outside the old age pension system, so that shortening the sample period may also lead to estimates that better represent the effect of current and future changes in the statutory age of retirement. Indeed, consistently with this explanation, the estimated coefficients on statutory pension ages increase as the estimation sample is shortened to include only the most recent years.

These effects lead to the conclusion that, for the majority of OECD countries considered in this paper, an increase in the statutory retirement age by one year might currently be expected to increase the average effective age of retirement by four to five months, which compares with estimates of around two months from a 
selection of cross-country estimations reviewed earlier in the paper. For countries where alternative early retirement pathways are important, the effect of an increase in statutory retirement ages is dampened. The extent of this dampening effect depends on whether alternative social security programmes act as a pipeline to retirement under an old age pension (with the pipeline shifting as statutory pensions ages change) or are an independent alternative to it. In the latter case, the responsiveness of the average age of retirement could be reduced by one third. A simulation of the effect of eliminating early retirement pathways based on the estimated equations, suggests that the participation rate of the age group 55-74 could be raised by up to 6 percentage points, equivalent to an increase in the average effective age of retirement of 18 months, whereas to achieve a similar effect without eliminating early retirement pathways would require an increase in the statutory retirement age by about four and a half years. Thus, tightening access to early retirement pathways would not only increase the responsiveness of the labour market to changes in the old age pension system, but lead to a substantial one-off increase in labour force participation and the average retirement age.

For countries where private pensions have a dominant role, the responsiveness of the average effective age of retirement to a change in statutory retirement ages is unsurprisingly found to be much lower, typically about half the response of the majority of countries. However, even for these countries it is possible that the long-run responsiveness of participation is understated, if changes in the public system eventually come to be reflected in private systems, albeit with a lag.

From the point of view of econometric methodology, this example provides a salutary warning about the dangers of trying to identify policy effects from pooled estimation coefficients, without taking into account heterogeneity across countries and through time, and from a focus on the statistical significance of coefficients rather than their magnitude and the plausibility of any implied policy effect.

\section{Disclosure statement}

Neither author has reported a conflict of interest. 
1. Blöndal, S. and Scarpetta, S., 1999. The Retirement Decision in OECD Countries. OECD Economics Department Working Papers, No. 202. https://doi.org/ $10.1787 / 565174210530$

2. Börsch-Supan, A. and Coile, C., 2018. Social Security Programs and Retirement Around the World: Reforms and Retirement Incentives - Introduction and Summary. NBER Working Papers, No. 25280. https://doi.org/10.3386/w25280

3. Börsch-Supan, A. and Jürges, H., 2012. Disability, Pension Reform and Early Retirement in Germany. In: D. Wise, ed. Social Security Programs and Retirement around the World: Historical Trends in Mortality and Health, Employment, and Disability Insurance Participation and Reforms. University of Chicago Press.

4. Duval, R., 2004. Retirement Behaviour in OECD Countries: Impact of Old-Age Pension Schemes and Other Social Transfer Programmes. OECD Economic Studies, (2), pp. 7-50. https://doi.org/10.1787/eco_studies-v2003-art8-en

5. Ebbinghaus, B., 2006. Reforming Early Retirement in Europe, Japan and the USA. Oxford: Oxford University Press. https://doi.org/10.1093/0199286116. 001.0001

6. Égert, B. and Gal, P., 2017. The quantification of structural reforms in OECD countries: A new framework. OECD Economics Department Working Papers, No. 1354. https://doi.org/10.1787/2d887027-en

7. Fischer, J. and Sousa-Poza, A., 2011. The Institutional Determinants of Early Retirement in Europe. SSRN Electronic Journal. http://dx.doi.org/10.2139/ ssrn.895081

8. Gal, P. and Theising, A., 2015. The macroeconomic impact of structural policies on labour market outcomes in OECD countries: A reassessment. OECD Economics Department Working Papers, No. 1271. https://dx.doi.org/10.1787/ 5 jrqc6t8ktjf-en

9. Geppert, C. [et al.], 2019. Labour supply of older people in advanced economies: the impact of changes to statutory retirement ages. OECD Economics Department Working Papers, No. 1554. https://doi.org/10.1787/b9f8d292-en

10. Grigoli, F., Koczan, Z. and Tapalova, P., 2018. Drivers of Labor Force Participation in Advanced Economies: Macro and Micro Evidence. IMF Working Papers, No. 18/150. https://doi.org/10.5089/9781484361528.001

11. Mastrobuoni, G., 2009. Labor supply effects of the recent social security benefit cuts: empirical estimates using cohort discontinuities. Journal of Public Economics, 93(11-12), pp. 1224-1233. https://doi.org/10.1016/j.jpubeco.2009.07.009

12. OECD, 2019. Pensions at a Glance. Paris: OECD.

13. OECD, 2010. Sickness, Disability and Work: Breaking the Barriers: A Synthesis of Findings across OECD Countries. Paris: OECD. https://doi.org/10.1787/ 9789264088856-en

14. Scherer, P., 2002. Age of Withdrawal from the Labour Force in OECD Countries. OECD Labour Market and Social Policy Occassional Papers, No. 49. https://doi.org/10.1787/327074367476 
15. Siegrist, J. [et al.], 2006. Quality of work, well-being, and intended early retirement of older employees-baseline results from the SHARE Study. European Journal of Public Health, 17(1), pp. 62-68. http://dx.doi.org/10.1093/eurpub/ ck1084

16. Staubli, S. and Zweimüller, J., 2013. Does raising the early retirement age increase employment of older workers? Journal of Public Economics, 108, pp. 17-32. https://doi.org/10.1016/j.jpubeco.2013.09.003 


\section{A1 The relationship between aggregate and single-age participation rates}

The aggregate participation rate of the age group 55-74, $P R^{55-74}$, is related to single-age participation rates, $P R^{a}$, according to:

$$
P R^{55-74}=\sum_{a=55}^{74} \theta^{a} P R^{a}
$$

where $\theta^{a}$ is the share of the population of age $a$ among the total population aged 55-74. For simplicity, it is assumed that the population is equally distributed over the ages $55-74$, so $\theta^{a}=1 / 20$ for all $a$, so:

$$
P R^{55-74}=\sum_{a=55}^{74} P R^{a} / 20
$$

Similarly, the aggregate participation rate of the age group 55-64, $P R^{55-64}$, is related to single-age participation rates as:

$$
P R^{55-64}=\sum_{a=55}^{64} P R^{a} / 10
$$

The assumption that the population is evenly distributed over the ages $55-74$, is approximate for the typical OECD country and is likely to become an even better approximation over the next 10 years (figure A1).

\section{Figure A1}

Older age population distribution of the average OECD country - Size of age group as a percentage of age group aged 55-74 (\%)

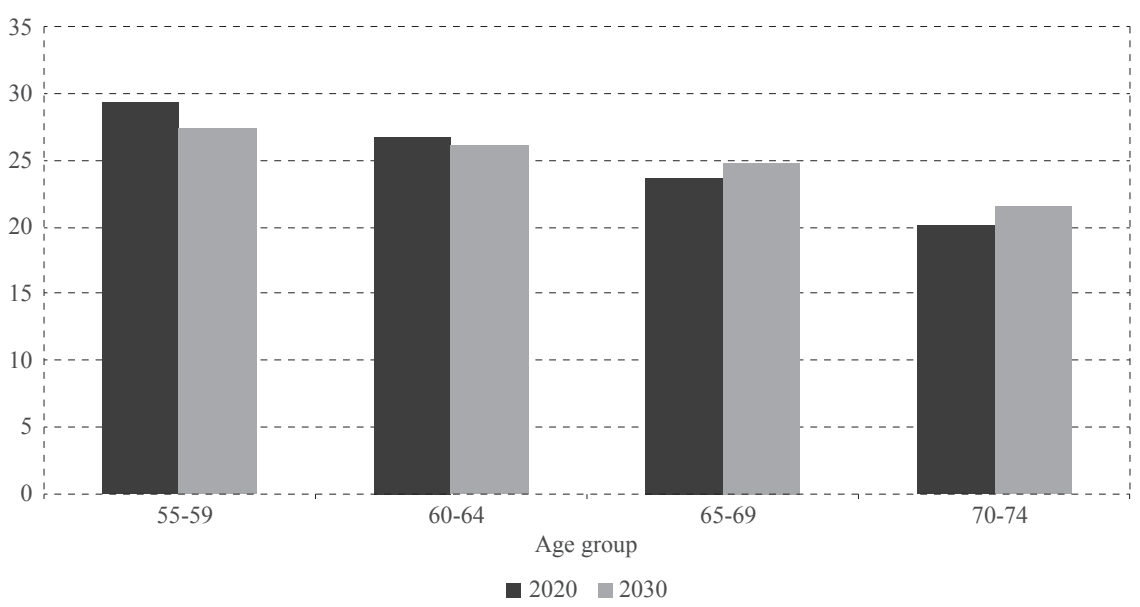

Note: Shares are calculated as unweighted averages of OECD countries.

Source: United Nations population estimates and projections. 
For the average OECD country, the proportion of the population in each of the age groups 60-64 and 65-69, which are likely to be most immediately affected by changes to statutory retirement ages, are close to being $25 \%$ of the population aged $55-74$.

\section{A2 Evaluating an estimated equation for participation modelled by single age} Suppose the single-age participation rate, $P R^{a}$ is modelled as:

$$
P R^{a}=-\beta_{\text {min }} D_{\text {min }}-\beta_{\text {norm }} D_{\text {norm }}+\text { other variables }
$$

where $D_{\min }\left(D_{\text {norm }}\right)$ are dummy variables taking the value of unity at ages equal to and above the minimum (normal) retirement age $a_{\text {min }}\left(a_{\text {norm }}\right)$ and "other variables" captures the effect of all other explanatory variables, which are assumed to remain unchanged following a pension reform. ${ }^{8}$

Then consider a reform that raises the minimum and normal retirement ages by one year. This is modelled by changing the dummy variables $D_{\min }$ and $D_{\text {norm }}$ : the dummy variable $D_{\min }$ changes from 1 to 0 at the pre-reform minimum retirement age (but is unchanged at all other ages); and, similarly, $D_{\text {norm }}$ changes from 1 to 0 at the pre-reform normal retirement age (but is unchanged at all other ages). Given (A4), the change in each dummy variable in only one year then raises older age participation by:

$$
\Delta P R^{55-74}=-\left(\beta_{\min }+\beta_{\text {norm }}\right) / 20
$$

So if $\beta_{\text {min }}=\beta_{\text {norm }}=-5$, as in the baseline model (see equation (1) in table 1), then:

$$
\triangle P R^{55-74}=+10 / 20=0.5 p p
$$

\section{A3 Effects on the average retirement age}

The average age of retirement (AAR) is the sum of each year of age weighted by the proportion of individuals leaving the labour force at that age. A simple "static" calculation of ARR, ignoring deaths, assuming the age structure is stable, that nobody retires before age 55 and everyone retires by age 75 , is given by: ${ }^{9}$

\footnotetext{
${ }^{8}$ The assumption that "other explanatory variables" are unaffected by the pension reform is a convenient simplification here. In the equations estimated in the full paper there is also an effect on participation from pension wealth and if the age-profile of pension wealth also shifts (as is likely) following a reform, then there will also be an effect from this channel. This second wealth channel is quantified in table 2 and in all calculations reported in the main paper, but not included in the algebra here, both because it is country-specific and because on average the effect on the participation rate and average age of retirement is relatively small. For example, for the baseline model (equation (1) in table 1), considering the effect on the average age of retirement from raising statutory pension ages by one year: the effect coming from the statutory retirement dummies alone is 1.6 months, but including an additional effect from pension wealth (assuming the age-profile is shifted up one year) only increases this estimate to 1.8 months.

${ }^{9}$ See Scherer (2010) for a proof of this static formula, which requires only cross-sectional data. He also points out that this static calculation will be different and potentially misleading compared to a dynamic calculation that allows for the evolving age structure of the population. The static calculation is used here because of it computational simplicity and because the only interest here is in evaluating the effect of a marginal change in the AAR in response to a policy change.
} 


$$
A A R=\sum_{a=55}^{75} \frac{P R^{a-1}-P R^{a}}{P R^{54}} \cdot a
$$

Now consider a reform that changes participation by $\triangle P R$ at each age, where " $\Delta$ " denotes the change following the reform, then the change in average retirement age is given by:

$$
\Delta A A R=\sum_{a=55}^{75} \frac{\Delta P R^{a-1}-\Delta P R^{a}}{P R^{54}} \cdot a
$$

Expanding the RHS of (A8) gives:

$$
\begin{aligned}
\Delta A A R= & \left(\frac{1}{P R^{54}}\right) \cdot\left[\left(\Delta P R^{54}-\Delta P R^{55}\right) 55+\ldots+\left(\Delta P R^{\min -1}-\Delta P R^{\text {min }}\right) \cdot a_{\text {min }}\right. \\
& +\left(\Delta P R^{\text {min }}-\Delta P R^{\text {min }+1}\right) \cdot a_{\text {min }+1}+\ldots+\left(\Delta P R^{\text {norm }-1}-\Delta P R^{\text {norm }}\right) \cdot a_{\text {norm }} \\
& \left.+\left(\Delta P R^{\text {norm }}-\Delta P R^{\text {norm }+1}\right) \cdot a_{\text {norm }+1}+\ldots\left(\Delta P R^{74}-\Delta P R^{75}\right) \cdot 75\right]
\end{aligned}
$$

Assuming the same model as described by (A3) above, the effect of a reform to increase statutory retirement ages by one year will be: firstly, to increase participation at the (pre-reform) minimum age of retirement by $-\beta_{\min }$ so that $\Delta P R^{\min }=-\beta_{\min }$; and secondly, participation increases by $-\beta_{\text {norm }}$ at the (pre-reform) normal age of retirement, so that $\triangle P R^{\text {norm }}=-\beta_{\text {norm }}$. The participation rate at all other ages remains unchanged, so that $\triangle P R^{a}=0$ for all $a \neq a_{\text {min }}$ or $a_{\text {norm }}$. Substituting into (A7) the change in AAR, as a result of the reform, is given by:

$$
\begin{aligned}
\triangle A A R= & \left(\frac{1}{P R^{54}}\right) \cdot\left[(0-0) \cdot 55+\ldots+\left(0-\beta_{\text {min }}\right) \cdot a_{\text {min }}+\left(\beta_{\text {min }}-0\right) \cdot a_{\text {min }+1}\right. \\
& \left.+\ldots+\left(0-\beta_{\text {norm }}\right) \cdot a_{\text {norm }}+\left(\beta_{\text {norm }}-0\right) \cdot a_{\text {norm }+1}+\ldots(0-0) \cdot 75\right]
\end{aligned}
$$

Further simplifying gives:

$$
\begin{gathered}
\triangle A A R=\left(\frac{1}{P R^{54}}\right) \cdot\left[\beta_{\text {min }}\left(a_{\text {min }}-a_{\text {min }+1}\right)+\beta_{\text {norm }}\left(a_{\text {norm }}-a_{\text {norm }+1}\right)\right] \\
\triangle A A R=-\frac{\left(\beta_{\min }+\beta_{\text {norm }}\right)}{P R^{54}}
\end{gathered}
$$

Then if the average participation rate at age 54 is $75 \%$ (which is close to an unweighted OECD average for 2018) and if $\beta_{\text {min }}=\beta_{\text {norm }}=-5$ as for the baseline equation in table 1, substituting into (A12) gives an estimate of the change in AAR for a one year increase in statutory retirement ages of:

$$
\triangle A A R=+\frac{10}{75}=0.13 \text { years }=1.6 \text { months }
$$


The estimated effect reported in table 1 for the baseline equation is based on this calculation plus a (small) separate addition to allow for the effect of pension wealth (which brings the total effect up to 2.4 months).

\section{A4 Using a transition-to-retirement variable instead of dummies}

Suppose instead of defining dummies at the minimum and normal retirement ages a transition-to-retirement age variable is defined to be zero before the minimum retirement age, unity above the normal retirement age, so that:

TRANS_RET $T^{a}=0$ if $a<a_{\text {min }} ; T R A N S \_R E T^{a}=1$ if $a>a_{\text {norm }}$;

and a fraction between these two ages, as follows:

TRANS_RET $T^{a}=\left(a+1-a_{\text {min }}\right) /\left(a_{\text {norm }}+1-a_{\text {min }}\right)$ if $a_{\text {min }} \leq a \leq a_{\text {norm }}$;

Then instead of estimating (A3), the following equation is estimated:

$$
P R^{a}=-\beta_{\text {trans }} \cdot \text { TRANS_RET } T^{a}+\text { other variables }
$$

Then the effect of an increase in both minimum and normal retirement ages by one year will affect participation at all ages between the (new) minimum and normal retirement ages, but the total change in the transition variable will be unity:

$$
\sum_{a=55}^{74} \Delta T R A N S_{-} R E T^{a}=1.0
$$

Consequently, instead of (A3) the change in the aggregate participation rate at older ages is given by:

$$
\Delta P R^{55-74}=-\beta_{\text {trans }} / 20
$$

So, rather than (A12), the change in the AAR is given by:

$$
\triangle A A R=-\frac{\beta_{\text {trans }}}{P R^{54}}
$$

A5 Evaluating an timated for articipation modelled as an age group aggregate Instead of participation being modelled by a single year of age, the older age participation rate is often modelled in other studies as a single variable for a particular age group such as the participation rate for those aged 55-64, so that:

$$
P R^{55-64}=\gamma_{\text {ret }} \cdot R E T+\text { other variables }
$$

where RET is a statutory retirement age. Then the effect of a 1-year shift in the statutory retirement age is given by:

$$
\Delta P R^{55-64}=\gamma_{\text {ret }}
$$


An expression for the aggregate participation rate of the age group 55-64, $P R^{55-64}$, in terms of the single-age participation rates was previously derived in (A3), so the effect of the change in policy will be as follows:

$$
\Delta P R^{55-64}=\sum_{a=55}^{64} \Delta P R^{a} / 10
$$

The effect of a change in policy, denoted by $\Delta$, on the average age of retirement is given by expression [A9], which can be applied to the age group 55-65 and rewritten as:

$$
\begin{aligned}
\triangle A A R= & \left(\frac{1}{P R^{54}}\right)\left[\left(\Delta P R^{54}-\Delta P R^{55}\right) \cdot 55+\left(\Delta P R^{55}-\Delta P R^{56}\right)\right. \\
& \cdot 56+\ldots+\left(\Delta P R^{62}-\Delta P R^{63}\right) \cdot 63+\left(\Delta P R^{63}-\Delta P R^{64}\right) \\
& \cdot 64+\left(\Delta P R^{64}-\Delta P R^{65} \cdot 65\right] \\
\triangle A A R= & \left(\frac{1}{P R^{54}}\right)\left[\Delta P R^{54} \cdot 55+\Delta P R^{55} \cdot(56-55)+\ldots+\Delta P R^{62} \cdot(63-62)\right. \\
+ & \left.\Delta P R^{63} \cdot(64-63)+\Delta P R^{64} \cdot(65-64)-\Delta P R^{65} \cdot 65\right] \\
\triangle A A R= & \left(\frac{1}{P R^{54}}\right)\left[\left(\Delta P R^{54}\right) \cdot 55+\Delta P R^{55}+\ldots+\Delta P R^{62}+\Delta P R^{63}\right. \\
+ & \left.\Delta P R^{64}-\Delta P R^{65} \cdot 65\right]
\end{aligned}
$$

But if everyone is assumed to retire between the ages 55 and $64, \triangle P R^{54}=\Delta P R^{65}=0$ then:

$$
\triangle A A R=\sum_{a=55}^{64} \frac{\Delta P R^{a}}{P R^{54}}
$$

Combining (A21) and (A20) to eliminate $\sum \Delta P R^{a}$ gives:

$$
\triangle A A R=10 \frac{\Delta P R^{55-64}}{P R^{54}}
$$

Then substituting $\triangle P R^{55-64}=\gamma_{\text {ret }}$ from (A19) gives an expression for the change in the average retirement age in years, following a change in the statutory age of retirement, which can be applied to an aggregate participation equation:

$$
\triangle A A R=\gamma_{\text {ret }} \frac{10}{P R^{54}}
$$


- Expression [A23] is used to compute the average age of retirement for most of the studies reported in table 1 of the main paper, on the assumptions that $P R^{54}=85 \%$ for men and $P R^{54}=75 \%$ for the total population (which are close to unweighted averages for OECD countries in 2018).

- Blöndal and Scarpetta (1999) report a coefficient $\gamma_{\text {ret }}$ of between 0.8 and 1.0 on regressions where the dependent variable is the male participation rate for those aged 55-64. So using (A23) and assuming $P R^{54}=85 \%$, this gives a value for $\triangle A A R$ of between 1.1 and 1.4 months, as reported in section 2 .

- The panel regressions reported by Duval (2004) consider the determinants of the percentage change between successive 5-year groups of male participation rates. Estimated coefficients on the statutory pension age determining the percentage change in participation between ages 55-59 and 60-64 and between 60-64 and 65-69 are 1.63 and 1.17, respectively (see model B in table 2 of the paper). Assuming that typical male participation rates for the age groups 55-59 and 60-64 are 80\% and 60\%, respectively, raising the statutory pension age by one year (assuming no effect on the age group 55-59) will raise the average participation rate of the entire age group 55-69 by about $(0 \cdot 5+80 / 100 \cdot 1.63 \cdot 5+60 / 100 \cdot 1.17 \cdot 5) / 15=2 / 3$ of a percentage point. Adapting the formula in (A23), this implies an increase in the average age of retirement of $2 / 3 \cdot 15 \cdot 1 / P R^{54}$ years. Further assuming $P R^{54}=85 \%$, this gives a value for $\triangle A A R$ of 1.4 months, as reported in section 2 .

- Egert and Gal (1999) report a coefficient $\gamma_{\text {ret }}$ of 0.85 on a regression where the dependent variable is the employment rate for those aged 55-64 (male and female). So, using (A23) and assuming that a change in statutory retirement ages leaves the older age unemployment rate unchanged (so that the change in the employment rate is reflected in the labour force participation rate) and $P R^{54}=75 \%$, gives a value for $\triangle A A R$ of 1.4 months, as reported in section 2 .

- Grigoli, Koczan and Tapalova (2018) report a coefficient $\gamma_{\text {ret }}$ of 0.66 on a regression where the dependent variable is the participation rate for those aged 55+. Using (A23) and $P R^{54}=75 \%$ gives a value for $\triangle A A R$ of 1.1 months. However, a further scaling adjustment needs to be made because the dependent variable in this case is the participation rate of those aged $55+$ (not 55-64 as in (A17)). Assuming that the changes in labour force participation from historical changes in the statutory retirement age in their sample mainly occurred over the ages 55-64, then to be comparable with the other calculations, the result needs to be scaled up by the inverse of the share of the population aged 55-64 relative to the population aged 55+. For OECD countries this share is currently about one-half, so the final estimate for $\triangle A A R$ is $2.2(=1.1 / 0.5)$ months, as reported in section 2 . 